\title{
Time-Varying Correlations between Trade Balance and Stock Prices in the United States over the Period 1792 to $2013^{\#}$
}

\author{
Nikolaos Antonakakis \\ Webster Vienna Private University, Department of Business and Management, Praterstrasse 23, 1020, \\ Vienna, Austria \\ University of Portsmouth, Department of Economics and Finance, Portsmouth Business School, Portland \\ Street, Portsmouth, PO1 3DE, United Kingdom \\ Rangan Gupta \\ Department of Economics, Faculty of Economic and Management Sciences, University of Pretoria, 0002, \\ South Africa \\ Aviral K. Tiwari \\ Montpellier Business School, Montpellier, France; Faculty of Management, IBS Hyderabad, IFHE \\ University, Donthanapally Shankarapalli Road, Hyderabad, Andhra Pradesh 501203, India
}

\begin{abstract}
The relationship between stock prices and the trade balance can be either negative or positive, depending on the signs of the wealth effect channel and the exchange rate channel. While previous studies examined this relationship in a time-invariant framework, we employ a time-varying approach so as to examine the dynamic correlations of trade balance and stock prices in the United States over the period 1792-2013. The results of our empirical analysis, which remain robust to alternative specifications, reveal that correlations between the trade balance and stock prices in the United States are indeed not constant, but evolve heterogeneously overtime. In particular, the correlations are, in general, significantly positive between 1800 and 1870, while significantly negative thereafter. The policy implications of these findings are then discussed.
\end{abstract}

Keywords: Conditional correlation, GARCH, Trade-Balance and Stock Price Comovement, US Economy

JEL codes: F3, F4, E44, C5, N1

\footnotetext{
\# We would like to thank two anonymous referees for many helpful comments. However, any remaining errors are solely ours.
} 


\section{Introduction}

As we know, a trade deficit occurs when a country does not produce enough goods for its residents. Alternatively, a deficit arises when a country's consumers are wealthy enough to purchase more goods than the country produces. Economic theory dictates that a trade deficit is not necessarily a bad situation because it often corrects itself over time. An increase in imported goods from other countries decreases the price of consumer goods in the nation as foreign competition increases, which in turn, reduces the threat of domestic inflation. An increase in imports also increases the variety and options of goods and services available to residents of a country. It is expected that a fast-growing economy would pull in more imports as it expands to allow its residents to consume more than the country can produce. So, in some cases, a trade deficit could signal a growing economy.

However, in the long run, a persistently growing trade deficit may lead to fewer jobs created. If the country is importing more goods from foreign companies which compete with its domestic companies, the domestic companies may eventually be driven out of business due to the lower prices that ensue. Manufacturing companies are usually hit the hardest when a country imports more than it exports as loss of jobs and incomes for its employees can be traced to the increase in competition from imports. The loss of jobs could lead to even fewer goods being produced in the economy which, in turn, could lead to even more imports and a wider deficit.

The US trade deficit in 2013 stood at 2.2 percent of GDP ( $\$ 478$ billion), which however, was lower when compared to the post World War II record high of 6.2 percent of GDP (\$762 billion) in 2006. But when we look at the history of trade deficit of the US over 1792 to 2013, highest numbers of 7.3 percent of GDP were recorded in 1808 and 1816 (see Figure 1). On average, as indicated in Table 1, the trade deficit has been 0.5 percent of GDP over the period of 1792 to 2013 - our period of analysis, ${ }^{1}$ with the deficit having a growing trend since 1980, which has economists worried and search for factors that determine the trade balance.In this regard, besides standard trade related

\footnotetext{
${ }^{1}$ In 2016, US exports were $\$ 2.2$ trillion and imports were $\$ 2.7$ trillion., with the trade deficit being about $\$ 500$ billion.
} 
factors $^{2}$, and macroeconomic shocks (productivity, monetary and fiscal shocks), the role of real stock prices on the U.S. trade balance ${ }^{3}$, as well as internationally, have been analysed recently by a number of studies. Not only empirical approaches, based on constant-parameter Vector Autoregressive (VAR) and Vector Error-Correction (VEC) models (see for example, Fratzscher and Straub, 2009, 2010; Kitamura, 2009; Fratzscher et al., 2010; Holinski and Vermeulen, 2012; Ncube and Ndou, 2013) have been utilized; theoretical general equilibrium models (see for example, Mercereau, 2003a,b; Kitamura, 2009; Fratzscher and Straub, 2010) have also been developed.

There exist primarily two channels through which real stock prices can influence the trade balance, namely the wealth effect channel and to some extent, through the exchange rate channel. Under the wealth effect channel, the general underlying logic is that a rise in stock prices, especially if it is considered to be permanent, increases expected income of households and hence consumption, while also making it easier for firms to finance investment opportunities, thus inducing a decline in a specific country's trade balance (Fratzscher and Straub, 2010). But as pointed out by SimoKengne et al. (2015), it is also possible that stakeholders draw on their wealth during stock market booms to increase their financial investment and, hence, reduce their consumption. In other words, the wealth effect can either increase or decrease consumption, thus deteriorating or improving the trade balance. As far as the exchange rate channel is concerned, an increase in real stock prices tends to have a positive impact on short-term interest rates and inflation, and leads to an appreciation of the real effective exchange rate and a sizeable increase in consumption, and thus deterioration of the trade balance (Fratzscher and Straub, 2009). However, the trade-balance can also have an impact on stock prices, with an increase in trade balance being inflationary and leading to a response from the monetary authority through higher interest rate, which, in turn is likely to negatively affect stock prices (Hogan et al., 1991; Aggarwal and Schirm, 1992, 1998; Mercereau, 2003a,b). In sum, both stock prices and trade-balance can affect each other, with the

\footnotetext{
${ }^{2}$ The cost of production (land, labor, capital, taxes, incentives, etc.) in the exporting economy vis-à-vis those in the importing economy; The cost and availability of raw materials, intermediate goods and other inputs; Exchange rate movements; Multilateral, bilateral and unilateral taxes or restrictions on trade; Non-tariff barriers such as environmental, health or safety standards; The availability of adequate foreign exchange with which to pay for imports; and Prices of goods manufactured at home (influenced by the responsiveness of supply)

${ }^{3}$ The literature studies the trade balance, rather than the current account, as researchers are interested in the effect of asset price shocks on net exports and want to exclude the effect on income (Fratzscher and Straub, 2009, 2010; Fratzscher et al., 2010).
} 
correlation between the variables being either negative or positive depending on which of the effects, discussed above, dominates.

Against this backdrop, the objective of our study is to analyse the evolution of the correlation between real stock price and trade-balance for the US economy using Engle (2002) dynamic conditional correlation (DCC)-GARCH model on annual data over the period of 1792-2013. ${ }^{4}$ Besides accounting for time-varying volatility behaviour of the data, a major advantage of the DCC-GARCH approach is its ability to detect changes in the conditional correlation over time. Moreover, it is able to distinguish negative correlations due to episodes in single years, synchronous behavior during stable years and asynchronous behavior in turbulent years. Unlike rolling windows, an alternative way to capture time variability, the proposed measure does not suffer from the so-called "ghost features", as the effects of a shock are not reflected in $n$ consecutive periods, with $n$ being the window span. In addition, under the proposed measure there is neither a need to set a window span, nor loss of observations, nor subsample estimation required. Note that, an ideal extension of literature would have been to use a sign-restricted time-varying VAR model, which would have allowed us to use time-varying impulse response functions to study the impact of shocks to stock prices and the trade balance. However, without data on consumption, which we do not have for this long-sample, separation of a stock price shock from other macroeconomic shocks would be impossible (Fratzscher and Straub, 2009, 2010; Fratzscher et al., 2010). In addition, it is also difficult to provide an interpretation to a stock price shock, with the literature being divided between a "news" shock or rational bubbles (Fratzscher and Straub, 2009, 2010; Fratzscher et al., 2010).

As discussed above, contingent on the strength of the channels at work, the relationship between real stock price and the trade balance could be either negative or positive. Hence, it is important to pursue a time-varying approach for analyzing the comovement between these variables to check the evolution of this relationship. The DCC-GARCH approach allows us to check if, in fact the relationship is indeed time-varying (state-contingent) or not, besides the nature of the relationship

\footnotetext{
${ }^{4}$ Ideally, we should be using real stock returns of the U.S. relative to its trading partners, since the trade balance of a country is intrinsically "relative", i.e., it expresses a relative flow. However, due to lack of data on equity returns on the major trading partners of the U.S. over this prolonged period, restricts us to consider real stock returns of the U.S. only. In this regard, our approach is similar to that of Fratzscher and Straub (2009).
} 
itself. A constant parameter approach, as has been applied so far in the literature, based on an average value of the correlation estimate is likely to be misleading in terms of policy, as it will not allow the policy maker to deduce the importance of the various effects that drive this relationship at specific points in time. So, besides the long sample period which allows us to track the history of U.S. trade balance in relationship to stock prices, our paper is the first attempt to provide a timevarying relationship between the two variables of interest.

Our empirical results reveal that correlations between the trade balance and stock market returns are indeed evolving heterogeneously overtime. In particular, the correlations are, in general, significantly positive between 1800 and 1870, and significantly negative thereafter, indicating the time-varying role of the various channels (discussed above) relating the stock market with the trade balance in the U.S.

The remainder of the paper is organized as follows: Section 2 describes the empirical methodology, while Section 3 the data used. Section 4 presents the empirical findings. Finally, Section 5 summarises the results, discusses their policy implications and offers some concluding remarks.

\section{Methodology}

In order to examine the evolution of co-movements between the trade balance and stock market returns, we obtain a time-varying measure of correlation based on the dynamic conditional correlation (DCC) model of Engle (2002).

Let $y_{t}=\left[y_{1 t}, y_{2 t}\right]^{\prime}$ be a $2 \times 1$ vector comprising the data series. The conditional mean equations are then represented by

$$
A(L) y_{t}=+\varepsilon_{t} \text {, where } \varepsilon_{t} \mid \Omega_{t-1} \sim N\left(0, H_{t}\right) \text {, and } t=1, \ldots, T
$$


where $A$ is a matrix of endogenous variables, $L$ the lag operator and $\varepsilon_{t}$ is the vector of innovations based on the information set, $\Omega$, available at time $t-1$. The $\varepsilon_{t}$ vector has the following conditional variance-covariance matrix

$$
H_{t}=D_{t} R_{t} D_{t}
$$

where $D_{t}=\operatorname{diag} \sqrt{h_{i t}}$ is a $2 \times 2$ matrix containing the time-varying standard deviations obtained from univariate $\operatorname{GARCH}(\mathrm{p}, \mathrm{q})$ models as

$$
h_{i t}=\gamma_{i}+\sum_{p=1}^{P_{i}} \alpha_{i p} \varepsilon_{i t-i p}^{2}+\sum_{q=1}^{Q_{i}} \beta_{i q} h_{i q-q}, \quad \forall i=1,2 .
$$

The DCC(M,N) model of Engle (2002) comprises the following structure

$$
R_{t}=Q_{t}^{*-1} Q_{t} Q_{t}^{*-1}
$$

where

$$
Q_{t}=\left(1-\sum_{m=1}^{M} a_{m}-\sum_{n=1}^{N} b_{n}\right) \bar{Q}+\sum_{m=1}^{M} a_{m}\left(\varepsilon_{t-m}^{2}\right)+\sum_{n=1}^{N} b_{n} Q_{t-n}
$$

$\bar{Q}$ is the time-invariant variance-covariance matrix retrieved from estimating equation (3), and $Q_{t}^{*}$ is a $2 \times 2$ diagonal matrix comprising the square root of the diagonal elements of $Q_{t}$. Finally, $R_{t}=$ $\rho_{i j_{t}}=\frac{q_{i j, t}}{\sqrt{q_{i i, t} q_{j, t}}}$ where $i, j=1,2$ is the $2 \times 2$ matrix consisting of the conditional correlations between the trade balance and stock market returns, and which are our main focus. 


\section{Data}

The two main variables of interest in this paper are the trade balance and the stock market prices in the US over the period of 1792-2013, i.e., 222 observations. The trade balance is measured as the difference between exports and imports as a \% of GDP, TB, and stock market prices are measured in real terms, i.e. deflated by the consumer price index (CPI) and then converted in real stock market returns, $R S R$, by taking the first difference of the natural logarithm of real stock prices, so as to render the series stationary. The data on trade balance as a \% of GDP comes from the Global Financial Database, i.e., both nominal trade balance: exports-imports and nominal GDP. The nominal S\&P500 stock price, which is deflated by the consumer price index (CPI) to get the real S\&P500, also comes from Global Financial Database. The CPI data is obatined from the website of Professor Robert Sahr. ${ }^{5}$

Figure 1 presents the evolution of the trade balance and real stock market returns. According to upper part of this figure, we observe that the US has experienced, in general, a trade deficit during the early (i.e. between 1792 and early 1870s) and recent (i.e. between mid-1870s and 2013) years of the sample period, while a trade surplus between the mid-1870s and the mid-1970s. Conversely, the stock market has experienced periods of positive returns followed by periods of negative returns; the latter occurred usually during recession periods in the U.S.

\section{[Insert Figure 1 around here]}

Table 1 presents the descriptive statistics of our data. According to this table, we observe large variability in our main variables, especially of the stock market returns. Over the last 222 years, the stock market in the United States has generated on average positive real returns equal to $1.5 \%$, while the trade balance was on average at deficit equal to 0.51 as a $\%$ of GDP. The augmented Dickey-Fuller (ADF) test with just a constant indicates that both series are stationary. The fact that the ARCH-LM test rejects the null hypothesis of homoskedasticity for each series indicates the appropriateness of modelling our series as an ARCH-type process. Finally, the unconditional

5 http://liberalarts.oregonstate.edu/spp/polisci/research/inflation-conversion-factors-convert-dollars-1774-estimated2024-dollars-recent-year. 
correlation between the trade balance and real stock market returns, which is presented in the lower panel of Table 1 , is negative and equal to -0.0448 .

[Insert Table 1 around here]

\section{Estimation Results}

Table 2 reports the results of the DCC model. Panels A and B present the conditional mean and variance results, respectively, while Panel C contains the Ljung-Box Q-Statistics on the standardized and squared standardized residuals up to 10 lags. The choice of the lag-length of the autoregressive process of the conditional mean, which is equal to two, is based on the Akaike information criterion (AIC) and Schwarz information criterion (SIC).

[Insert Table 2 around here]

According to the conditional mean results reported in Table 2, we find that past values of trade balance (i.e. the two previous years) and real stock market returns (i.e. the second year) are associated with significant increases in the current trade balance. Notably, the first period of real stock returns has a negative, albeit, insignificant effect on the trade balance as percentage of GDP, though the effect of the second lag is stronger. We observe that, past real stock market returns are significantly associated, on average, with higher current real stock market returns, with the positive effect of the first lag being stronger than the negative impact of the second lag. Interestingly, real stock returns not affected by any of the two lags of the trade balance, suggesting the exogeneity of the real stock returns, which in turn, is not surprising, given the evidence of poor stock market predictability (Welch and Goyal, 2008). So the channel associated with an increase in trade balance being inflationary and leading to a response from the monetary authority through higher interest rate, which in turn, is likely to negatively affect stock returns, is not present in the data.

The conditional variance results reported in the same table support the existence of the GARCH effects found in the series, as the coefficients $\alpha_{1}$ and $\beta_{1}$ are highly significant. Moreover, the coefficients $a$ and $b$ are highly significant indicating that the correlations between trade balance 
and real stock market returns are indeed time-varying. Both these results validate the choice of the DCC model. Finally, the model does not suffer from serial correlation in the squared (standardized) residuals, according to the misspecification tests reported in Panel C of Table 2.

In Figure 2, we present the dynamic conditional correlations of trade balance and real stock market returns estimated in Table 2, along with their $90 \%$ confidence intervals. According to this figure, it is evident that dynamic conditional correlations between trade balance and real stock market returns behaved rather heterogeneously overtime. In particular, correlations are, in general, significantly positive between 1800 and 1870, and significantly negative thereafter until 2013, indicating that during the early part of the sample, stakeholders were probably drawing on their wealth during stock market booms to increase their financial investment and, hence, reducing their consumption. This in turn, implied a positive correlation between the real stock returns and the trade balance. However, as the stock market started to develop, the traditional wealth and exchange rate effects started to drive the expected negative correlation between the two variables of interest. Based on the full-sample estimates, since we observe real stock returns to be exogenous in the system, we can say that the channel associated with an increase in trade balance being inflationary and leading to a response from the monetary authority through higher interest rate leading to negatively affecting the stock returns, is not necessarily playing an important role here. However, one must be also careful in drawing this line of reasoning, since, while the full-sample DCCGARCH estimates show a positive influence of the stock market on the trade balance, in fact, post 1870, the effect has been negative, and hence, aligned with theory. While, this is the first study to look at such a long span of data for the US economy, besides using a time-varying approach, our results are in line with the recent studies using post World War II data, which tends to associate deterioration of the trade balance with tremendous growth in stock prices (until the recent global financial crisis of 2007) in developed and emerging markets, and in particular in the US economy (see for example, Fratzscher and Straub (2009, 2010), and Fratzscher et al., (2010)). But differently from these studies, besides the positive relationship between trade balance and stock returns prior to 1870 , we show that the strength of the relationship is not constant over time, but varies significantly, with the effect having tremendously weakened when compared to the early 1920s, and especially after World War II. 
From the perspective of policy making, our results have important implications. First, we highlight that stock market movements have historically had a statistically significant relationship with trade balance of the US. Hence, policy-makers concerned with the deteriorating trade balance of the US, will need to carefully monitor the stock market too, besides other factors that drives the trade balance. More importantly, however, this monitoring needs to be done constantly, as the nature of the relationship, as well as, the size of this correlation tends to vary over time, contingent on which theoretical channel is at work. Reliance on the belief that the relationship between these two variables are unchanged using constant parameter econometric models, will lead to inaccurate policy decisions, as these models would give the average relationship over time and not how the correlation has evolved - something already pointed out through our results. In other words, policy makers need to realize that the relationship between these two variables is in fact nonlinear and a time-varying approach is necessary to appropriately model these two variables. Second, given that the relationship is time-varying in terms of both sign and size, the corresponding nature of policy intervention, i.e., its size and whether expansionary or contractionary policies should be pursued, should also be contingent on time, with policy-makers constantly evaluating the relationship at the point in time they decide to undertake a policy measure. Given that, as we show in this study, stock markets could also improve the trade balance rather than reducing it, policies designed to prevent exuberance in the stock market will not necessarily result in improvement of the trade balance. For this to take place, at the time of this policy decision, the relationship between stock market movements and the balance of trade should in fact be negative. An important, and controversial, related issue is however, whether policy-makers (both central bankers and fiscal authorities) should actually intervene in the stock market (see for example André et al., 2012, for a detailed discussion of policy intervention and asset market bubbles) to prevent deterioration of the trade balance, when the existing relationship between stock returns and trade balance is in fact negative. However, given the persistent trade deficit in the US, and its possible contractionary effect on the US economy, it would make sense for policy-makers to intervene in the stock market through contractionary monetary and fiscal policies to prevent overheating of the market, and prevent persistent deviation of the stock market from its fundamentals, i.e., stop bubbles from being developed. This is important, since if bubbles burst, this is likely to deepen the negative influence of the deteriorating trade balance, through a second round effect of a possible financial crisis, as witnessed recently in 2007 and afterwards. 
[Insert Figure 2 around here]

\subsection{Robustness analysis}

As a robustness check, we examined whether our dynamic conditional correlation results of the trade balance and real stock market returns are affected by using excess real stock market returns, as in Mercereau (2003a,b), instead of real stock market returns. This stems from the fact that agents are assumed to be risk-averse in asset-pricing models, and hence, agents have to expect that stocks will yield higher returns than the risk-free rate (i.e., "excess returns") on average for them to be compensated for the risk they undertake by holding "risky" equities. We thus construct excess (real) stock market returns as the difference between real stock market returns and real short-term interest rates. Nominal short-term interest rates (which are converted to real ones based on the CPI) are obtained over the period of 1800-1870 from Homer and Sylla (2005), and beyond that, from the data segment of the website of Professor Robert J. Shiller ${ }^{6}$.

The results of this robustness analysis which are reported in Table 3 and Figure 3 remain robust to those of our main findings. ${ }^{7}$ In particular, these results, with the only exception that dynamic correlations in the post-1870 period become significantly positive for a brief period, namely, around the Great Recession (see Figure 3), possibly capturing the collapse of the stock market, are very similar to those of our main analysis above.

[Insert Table 3 around here]

[Insert Figure 3 around here]

\section{Conclusion}

\footnotetext{
${ }^{6}$ http://www.econ.yale.edu/ shiller/data.htm.

${ }^{7}$ Some evidence that the trade balance reduces the real excess stock returns, and hence, the interest rate channel is at work can also be found now in Table 3, unlike what we observed for the real stock returns.
} 
The aim of this study was to examine time-varying correlation between trade balance and real stock market returns, in a time-varying framework over the period 1792-2013 in the United States. The results of our empirical analysis, which remain robust to alternative specifications, reveal that correlations between the trade balance and stock market returns in the United States are indeed evolving heterogeneously overtime. In particular, the correlations are, in general, significantly positive between 1800 and 1870, while significantly negative thereafter. Our results indicate that,

given the evolving relationship between real stock prices and trade balance, policy makers would be well-suited to rely on time-varying approaches, since the sign of this relationship is contingent on the nature of the underlying forces, which tend to vary over time too. More importantly, it is not guaranteed that policies designed to prevent exuberance in the stock market, will result in improvement of the trade balance. Thus, authorities need to first determine the dominant channel, at the point in time policy decisions are being made.

Given that the focus of this paper was to examine the time-varying comovement between stock prices and the trade balance, an avenue for future research would be to analyse the causal relationship between these two variables using wavelets. The wavelets-based approach would allow us to not only provide time-varying causal relationships, but also decompose this relationship across frequency domains, and hence provide evidence of short-, medium-, and longrun causality, along with the sign of the relationship.

\section{References}

Aggarwal, R., Schirm, D. C., 1992. Balance of Trade Announcements and Asset Prices: In uence on Equity Prices, Exchange Rates, and Interest Rates. Journal of International Money and Finance 11 (1), 80-95.

Aggarwal, R., Schirm, D. C., 1998. Asymmetric Impact of Trade Balance News on Asset Prices. Journal of International Financial Markets, Institutions and Money 8 (1), 83-100.

André, C., Gupta, R., and Kanda, P.T. (2012). Do House Prices Impact Consumption and Interest Rate? Evidence from OECD Countries using an Agnostic Identification Procedure. Applied Economics Quarterly 58(1), 19-70. 
Engle, R., 2002. Dynamic Conditional Correlation: A Simple Class of Multivariate General- ized Autoregressive Conditional Heteroskedasticity Models. Journal of Business \& Economic Statistics 20 (3), 339-50.

Fratzscher, M., Juvenal, L., Sarno, L., 2010. Asset Prices, Exchange Rates and the Current Account. European Economic Review 54 (5), 643-658.

Fratzscher, M., Straub, R., 2009. Asset Prices and Current Account Fluctuations in G-7 Economies. IMF Staff Papers 56 (3), 633-654.

Fratzscher, M., Straub, R., 2010. Asset Prices, News Shocks and the Current Account. CEPR Discussion Papers 8080.

Hogan, K., Melvin, M., Roberts, D. J., 1991. Trade Balance News and Exchange Rates: Is There a Policy Signal? Journal of International Money and Finance 10 (1, Supple), S90-S99.

Holinski, N., Vermeulen, R., 2012. The International Wealth Channel: A Global Error- Correcting Analysis. Empirical Economics 43 (3), 985-1010.

Homer, S., Sylla, R., 2005. A History of Interest Rates. Wiley Finance. Kitamura, Y., 2009. The Current Account and Stock Returns. Research in International Business and Finance 23 (3), 302-321.

Mercereau, B., 2003a. The Role of Stock Markets in Current Account Dynamics: a Time Series Approach. The B.E. Journal of Macroeconomics 3 (1), 1-30.

Mercereau, B., 2003b. The Role of Stock Markets in Current Account Dynamics: Evidence from the United States. IMF Working Papers 03/108, International Monetary Fund.

Ncube, M., Ndou, E., 2013. Monetary Policy and Exchange Rate Shocks on South African Trade Balance. Working Paper Series 448, African Development Bank.

Simo-Kengne, B., Miller, S., Gupta, R., Aye, G., 2015. Time-Varying Effects of Housing and Stock Returns on U.S. Consumption. The Journal of Real Estate Finance and Economics 50 (3), 339-354.

Welch, I., and Goyal, A. (2008). A Comprehensive Look at Empirical Performance of Equity Premium Prediction. Review of Financial Studies 21(4), 1455-1508. 
Figure 1: Trade balance and real stock market returns
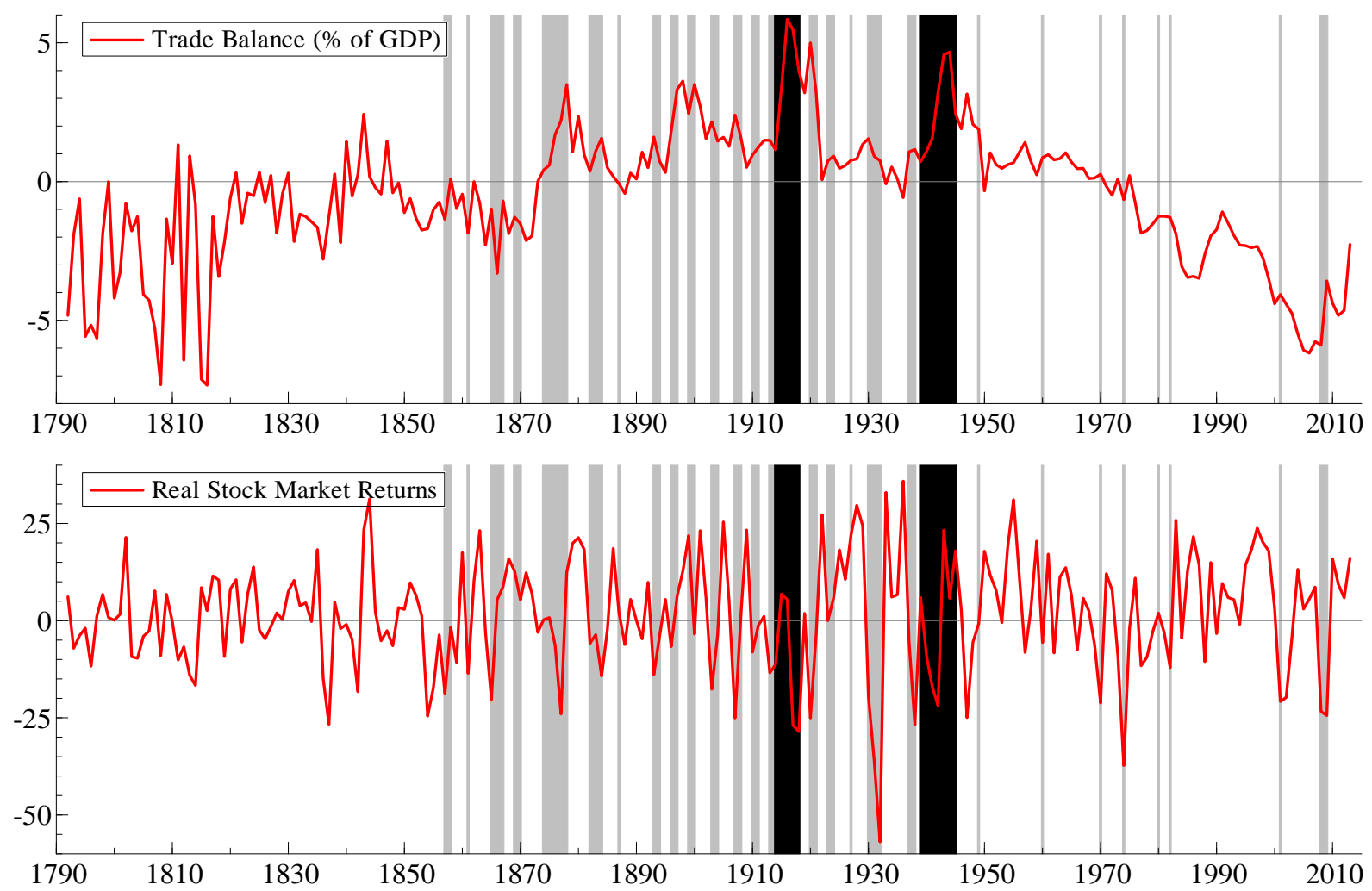

Note: Shaded grey areas denote US recessions as defined by the National Bureau of Economic Research (NBER) and shaded black areas denote world wars. 
Figure 2: Dynamic conditional correlations between trade balance and real stock market returns

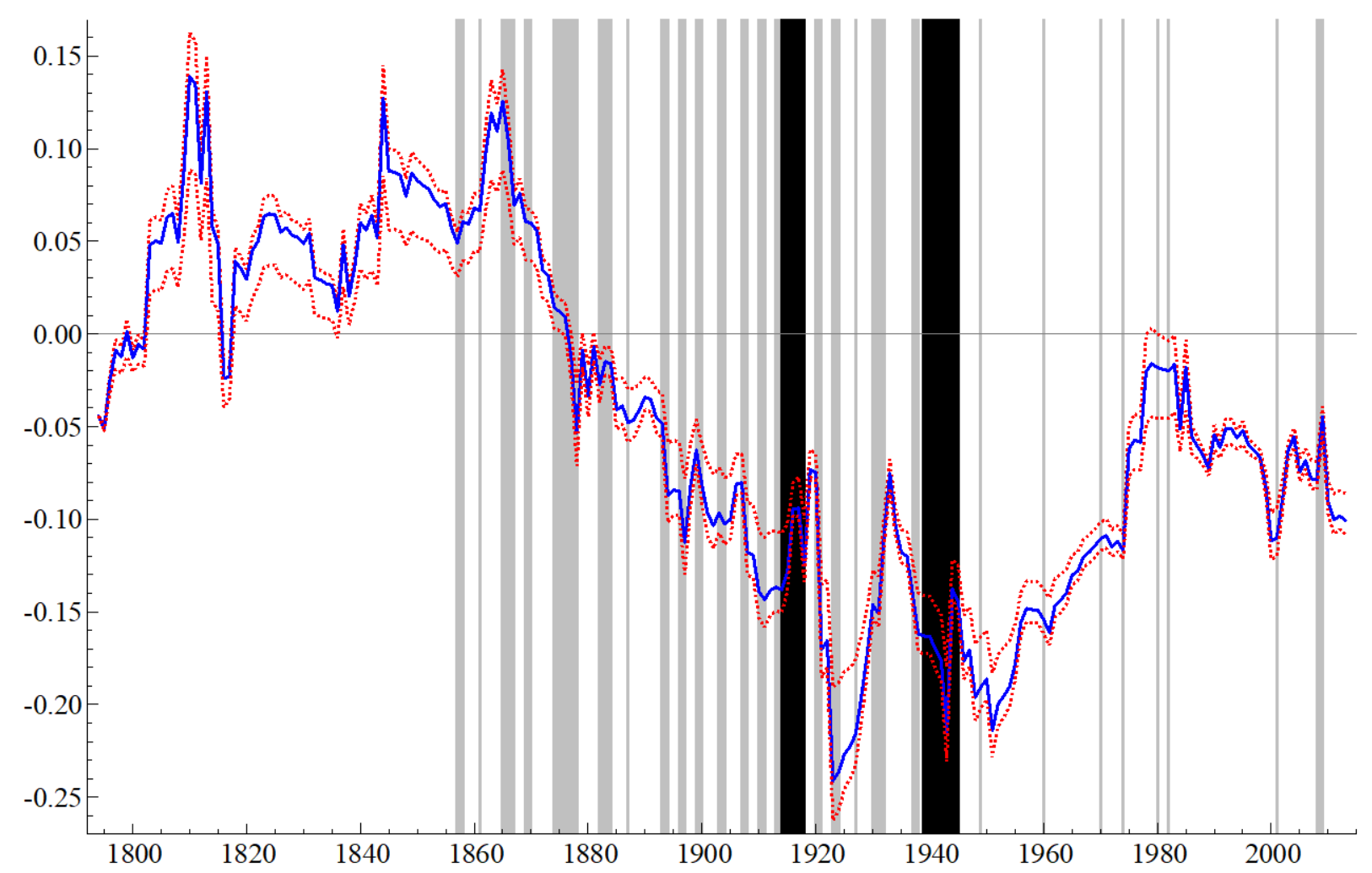

Note: Dotted lines are the $90 \%$ confidence intervals. Shading denotes US recessions as defined by NBER and shaded black areas denote world wars. 
Figure 3: Dynamic conditional correlations between trade balance and excess real stock market returns

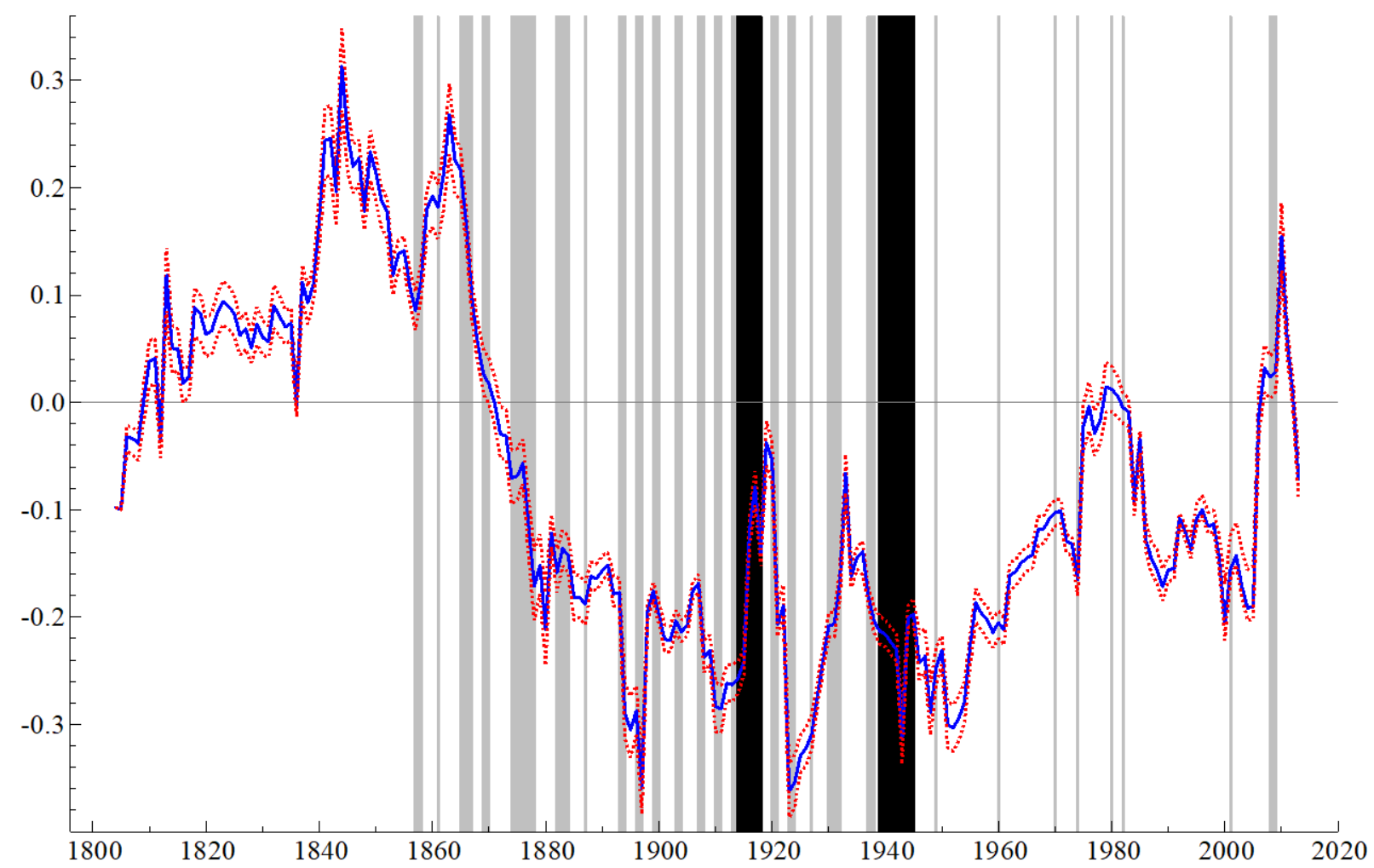

Note: Dotted lines are the $90 \%$ confidence intervals. Shading denotes US recessions as defined by NBER and shaded black areas denote world wars. 
Table 1: Descriptive statistics

\begin{tabular}{lll}
\hline \hline & Trade Balance & Real Stock Market Returns \\
\hline Min & -7.3354 & -56.8882 \\
Mean & -0.5097 & 1.5052 \\
Max & 5.8453 & 35.8984 \\
Std & 2.4358 & 14.2832 \\
Skewness & -0.4424 & -0.4235 \\
Kurtosis & $3.4060^{* *}$ & $3.7848^{* *}$ \\
Jarque-Bera & $8.7650^{*}$ & $12.3326^{* *}$ \\
ADF $^{a}$ (constant) & $-3.5427^{* *}$ & $-11.0448^{* *}$ \\
ARCH(10) LM Test $^{*}$ & $16.5390^{* *}$ & $3.4952^{* *}$ \\
\hline Trade Balance & \multicolumn{2}{l}{ Unconditional Correlations } \\
\cline { 2 - 2 } Real Stock Market Returns & -0.0448 & 1.0000 \\
\hline \hline
\end{tabular}

Note: ${ }^{a}$ The $5 \%$ and $1 \%$ critical values are -2.87 and -3.46 , respectively. $*$ and $* *$ indicate significance at $5 \%$ and $1 \%$ level, respectively. 
Table 2: Estimation results of DCC-GARCH model between trade balance and real stock market returns, Period: $1792-2013$

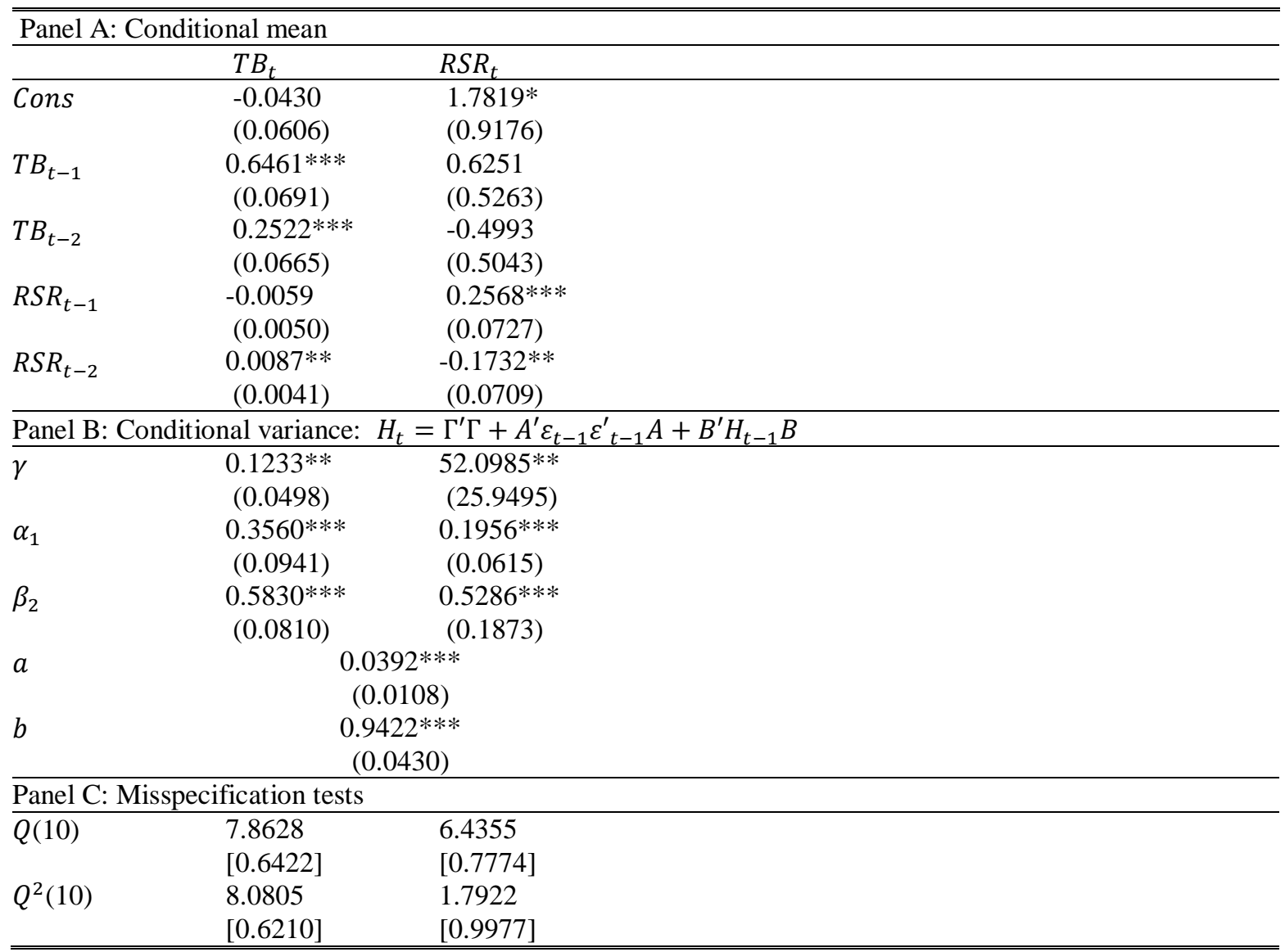

Note: $T B_{t}$ and $R S R_{t}$ denote the trade balance as a \% of GDP, and real stock markets returns, respectively, at time $t$. 2 lags in the conditional mean equations were suggested by the Akaike Information Criterion (AIC) and Schwarz Bayesian Criterion (BIC). $Q(10)$ and $Q^{2}(10)$ are the Ljung-Box Q-Statistics on the standardized and squared standardized residuals, respectively, up to 10 lags. Standard Errors in parenthesis and p-values in square brackets. *, $* *$ and $* * *$ denote statistical significance at the $10 \%, 5 \%$ and the $1 \%$ level, respectively. 
Table 3: Estimation results of DCC-GARCH model between trade balance and excess real stock market returns, Period: 1792 - 2013

\begin{tabular}{|c|c|c|}
\hline \multicolumn{3}{|c|}{ Panel A: Conditional mean } \\
\hline & $T B_{t}$ & $E R S R_{t}$ \\
\hline \multirow[t]{2}{*}{ Cons } & -0.0290 & $3.2856^{* *}$ \\
\hline & $(0.0582)$ & $(1.3234)$ \\
\hline \multirow{2}{*}{$T B_{t-1}$} & $0.6545 * * *$ & 0.7049 \\
\hline & $(0.0225)$ & $(0.5279)$ \\
\hline \multirow{2}{*}{$T B_{t-2}$} & $0.1956 * * *$ & $-0.9418 *$ \\
\hline & $(0.0228)$ & $(0.5201)$ \\
\hline \multirow{2}{*}{$T B_{t-3}$} & $0.0469 * *$ & 0.0783 \\
\hline & $(0.0231)$ & $(0.5255)$ \\
\hline \multirow{2}{*}{$E R S R_{t-1}$} & -0.0035 & 0.0313 \\
\hline & $(0.0023)$ & $(0.0821)$ \\
\hline \multirow{2}{*}{$E R S R_{t-2}$} & 0.0027 & $-0.1544 * *$ \\
\hline & $(0.0025)$ & $(0.0729)$ \\
\hline \multirow{2}{*}{$E R S R_{t-3}$} & 0.0030 & 0.0360 \\
\hline & $(0.0024)$ & $(0.0718)$ \\
\hline \multicolumn{3}{|c|}{ Panel B: Conditional variance: $H_{t}=\Gamma^{\prime} \Gamma+A^{\prime} \varepsilon_{t-1} \varepsilon^{\prime}{ }_{t-1} A+B^{\prime} H_{t-1} B$} \\
\hline \multirow[t]{2}{*}{$\gamma$} & $0.1499 * * *$ & $125.1401 * * *$ \\
\hline & $(0.0230)$ & $(16.2355)$ \\
\hline \multirow[t]{2}{*}{$\alpha_{1}$} & $0.3827 * * *$ & $0.3086 * * *$ \\
\hline & $(0.0590)$ & $(0.0586)$ \\
\hline \multirow{2}{*}{$\beta_{2}$} & $0.5310 * * *$ & $0.4361 * * *$ \\
\hline & $(0.0326)$ & $(0.0453)$ \\
\hline \multirow{2}{*}{\multicolumn{2}{|c|}{$a$}} & $* *$ \\
\hline & & \\
\hline \multirow[t]{2}{*}{$b$} & & \\
\hline & & \\
\hline \multicolumn{3}{|c|}{ Panel C: Misspecification tests } \\
\hline \multirow[t]{2}{*}{$Q(10)$} & 6.0511 & 2.5378 \\
\hline & {$[0.8110]$} & [0.9903] \\
\hline \multirow[t]{2}{*}{$Q^{2}(10)$} & 8.8474 & 5.0859 \\
\hline & {$[0.5466]$} & {$[0.8854]$} \\
\hline
\end{tabular}

Note: $T B_{t}$ and $E R S R_{t}$ denote the trade balance as a \% of GDP, and excess real stock markets returns, respectively, at time $t .3$ lags in the conditional mean equations were suggested by the Akaike Information Criterion (AIC) and Schwarz Bayesian Criterion (BIC). $Q(10)$ and $Q^{2}(10)$ are the Ljung-Box Q-Statistics on the standardized and squared standardized residuals, respectively, up to 10 lags. Standard Errors in parenthesis and p-values in square brackets. *, ** and $* * *$ denote statistical significance at the $10 \%, 5 \%$ and the $1 \%$ level, respectively. 